Original article

\title{
Accomplices of job burnout among employees of a medical university
}

\author{
Iman Seyedmoharrami ${ }^{1,2}$, Khaula Atif ${ }^{3}$, Maryam Tatari ${ }^{1}$, Sedigheh Abbaspour ${ }^{1}$, Anahita Zandi ${ }^{1}$, \\ Gholamheidar Teimori-Boghsani ${ }^{1}$, Abbas Ghodrati-Torbati ${ }^{1}$ \\ ${ }^{1}$ Torbat Heydariyeh University of Medical Sciences, Torbat Heydariyeh, Iran \\ ${ }^{2}$ Ferdowsi University of Mashhad, Mashhad, Iran \\ ${ }^{3}$ National University of Medical Sciences, Rawalpindi, Pakistan
}

Received 26 March 2018, Revised 13 October 2018, Accepted 15 October 2018

(C) 2018, Seyedmoharrami I., Atif K., Tatari M., Abbaspour S., Zandi A., Teimori-Boghsani G., Ghodrati-Torbati A

(C) 2018, Russian Open Medical Journal

Abstract: Aim - Burnout is one of the major occupational hazards that precludes the efficiency and wastes human resources. The aim of this study was to determine the prevalence of job burnout and its related factors among the staff of a Medical University in Iran.

Material and Methods - In this simple descriptive, Knowledge-Attitude-Practice educational cross-sectional study, 250 employees were enrolled randomly via non-purposive sampling technique in 2016. Standardized Maslach Job burnout Inventory (MBI) and organizational climate questionnaire were used as instruments. Data analysis was performed using Mann-Whitney, Kruskal-Wallis and Chi-2 tests. P-value less than 0.05 was considered as significant.

Results - Mild, moderate and severe levels of job burnout were revealed by $66.4 \%, 25.6 \%$ and $7.6 \%$ respectively; while 28 (11.2\%), 56 $(22.4 \%)$ and $166(66.4 \%)$ endorsed weak, moderate and strong organizational climate scores. There was significant negative relation between job burnout and organizational climate level $(p<0.001)$. There was no significant impact of gender $(p=0.782)$, employment type $(p=0.672)$, work experience $(p=0.48)$, and work unit $(p=0.222)$ on outcome variable. None of the demographic variables had significant impact on organizational climate scores.

Conclusion - A positive and employee-friendly organizational climate is mandatory to diminish the prevalence and arrest the incidence of job burnout in every set-up. Affected employees must be identified and adequately managed.

Keywords: doctors, health-care providers, organizational climate, psychological stress.

Cite as Seyedmoharrami I, Atif K, Tatari M, Abbaspour S, Zandi A, Teimori-Boghsani G, Ghodrati-Torbati A. Accomplices of job burnout among employees of a medical university. Russian Open Medical Journal 2019; 8: e0105.

Correspondence to Gholamheidar Teimori-Boghsani. E-mail: teimorigh1@gmail.com.

\section{Introduction}

Employees are the linchpin of any industry. Production and productivity of every organization mandate physically and mentally healthy underlings. No organization can suffice without proper environment. Currently, occupational burnout is a perplexing concern for any department; health care providers being no exception. Job burnout is an occupational hazard that imparts psychosomatic effects on workers, thus precludes efficiency and wastes human resources [1]. Merriam Webster defines burnout as "Exhaustion of physical or emotional strength or motivation usually as a result of prolonged stress or frustration". This psychiatric syndrome may manifest as emotional exhaustion, depersonalization or attenuated sense of success. Occupational stress is a vital accomplice to induce a multitude of physical/mental illnesses, negative attitude towards professional activities and shoddier communication with the clients [2,3]. Job burnout has been endorsed by scientists from Iran $[4,5]$, China $[1,6]$ and European countries [7]; it is documented that in any work group, one in seven subjects faces burnout [4].
Health sector is one of the most important areas for sustainable development of human societies as it casts direct or indirect effects on wellbeing of its people. Unhealthy doctors may knowingly or unknowingly impart paradoxical adversities to their clients. Almost 30\% doctors decree distress [3]. Distressed doctors can seldom render their best services to their organization $[3,4]$. Mental distress and job burnout diminish job satisfaction and may hamper patient care $[3,5,8]$. Apropos, a league of mentally and physically robust doctors is obligatory for foundation and sustenance of a stout society $[8,9]$.

The link between organizational climate and work output in any unit can never be over-emphasized. It's a measure of perception regarding internal environment of a department by employees or outsiders [10]. Better occupational environment enhances job satisfaction and curtails distress among handlers [ 1 , 8, 11]; while inadequacies seed burnout. Unambiguously, any alterations in workplace climate lead to immediate and profound transformation in work outputs [1]. Various organizational 
criteria/indicators can divulge workers' physical or mental stress; apposite instruments are available to methodically measure these parameters. Maslach Job burnout Inventory (MBI) is a key instrument, which is a frequently incorporated, validated and reliable instrument to measure burnout [12]. It probes into emotional exhaustion, depersonalization and personal accomplishment. Organizational climate questionnaire was developed by Sussman and Deep (1986) [13]. Its 20 questions measure subscales of lucidity of goals, precision of role, effective communications, and reception of system and reward acknowledgement. These features describe organizational influences on the behavior of its employees [9]. Job burnout and contentment with organizational climate among health-facilitators could never gather due attention of researchers all over the world; literature is even more skimpy from Iran. Likelihood of any detrimental effects of mental health state of medical/paramedical staff on general public led the authors to design this research.

We aimed to measure prevalence of job burnout among subjects and unveil probable accomplices. It was hypothesized that participants harbor significant occupational burnout; all independent variables were suspected as potential accomplices. We hope that inferences drawn from this study may help researchers and managements to address any negative associations of job burnout and occupational climates at every echelon of various local, regional or international organizations.

\section{Material and Methods}

\section{Study participants and setting}

In this simple descriptive, Knowledge-Attitude-Practice educational cross-sectional study, conducted at Torbat Heydariyeh University of Medical Sciences (Torbat Heydariyeh, Iran), from Jan 2016 to Dec 2016, Prior permission from relevant ethical review board was sought. Required sample size using the Morgan table and basing on the size of the community was 250 subjects. Total employees in the concerned university at the time of research were 720 . Primary inclusion criterion was at least 2 years of work experience at the concerned University; those with lesser service or any diagnosed mental health ailment were excluded. First 250 participants who met the criteria and endorsed informed consent were enrolled by random non-purposive technique.

\section{Measures}

Participants were assessed by using a self-designed questionnaire collecting demographic information (gender, type of employment, work experience and workplace). Standardized Maslach Job burnout Inventory (MBI) and Sussman \& Deep Organizational Climate Questionnaire (OCQ) were the study instruments (Iranian versions).

MBI has a Coefficient Cronbach's alpha for the exhaustion 88, cynicism 90, and academic efficacy 84 [12]. Maslach and Jackson reported a coefficient of internal reliability for emotional exhaustion of 0.9 , depersonalization of 0.79 and Personal Accomplishment of 0.71 [14]. Its closed-ended items comprise of Emotional Exhaustion, Depersonalization and Personal Accomplishment, answers base on Likert scale 1-6 (very good to very bad). Cut-off values were following; emotional exhaustion score $\geq 25$, personalization score $\geq 11$, and reduced accomplishment $\geq 16$. All three scales scoring less than cut-off meant no burnout; scores of one, two or three scales beyond cutoff qualified for mild, moderate of severe burnout respectively.

Organizational climate questionnaire of Sussmaan and Deep is widely accepted $[9,15,16]$, it was validated with 0.89 Cronbach's alpha coefficient [17]. The OCQ carries 20 descriptive words and scored according to Likert scale (totally agree to totally disagree). The total score ranged from 0 to 80 , scores 0-27 showed weak, 2740 moderate and $\geq 40$ strong organizational climate. In the present study, the validity of OCQ was $0.76 \%$.

\section{Statistical analysis}

The statistical analysis was performed using SPSS (version 21, SPSS Inc., Chicago, IL, USA), Mann-Whitney, Kruskal-Wallis and Chi2 tests. Considering that the response variable (job burnout) is an ordinal variable, nonparametric tests were used. Quantitative data expressed as mean, standard deviation, minimum and maximum $\mathrm{M} \pm \mathrm{SD}$ (min-max); qualitative - as frequency (percentage). P-value less than 0.05 was considered as significant.

\section{Results}

Age of the respondents was $34.53 \pm 7.70$ years. Qualitative variables are highlighted in Table 1 . The organizational climate scores were $62.78 \pm 49.39$ (11-481); those for job burnout were $64.96 \pm 13.43$ (20-92). Weak, moderate and strong organizational climate scores were endorsed by $28(11.2 \%), 56(22.4 \%)$ and $166(66.4 \%)$ respectively; while 167 (66.8\%) respondents had mild, $64(25.6 \%)$ moderate and 19 (7.6\%) had severe levels of job burnout respectively.

There was significant negative relation between job burnout and organizational climate level $(p<0.001)$ (Figure 1$)$; former attenuated with escalating organizational climate scores. Figure 2 illustrates that participants with weak organization climate homogenously depicted more occupational burnout. Severe burnout was found in $14.2 \%, 7.2 \%$ and $6.5 \%$ employees with weak, moderate and strong organizational climate respectively. There was no significant impact of gender $(p=0.782)$, employment type $(p=0.672)$, work experience $(p=0.480)$, and work unit $(p=0.222)$ on outcome variable (Table 1). Similarly, organizational climate levels had no significant effect of gender $(p=0.544)$, work experience $(p=0.746)$, employment type $(p=0.630)$ or working group $(p=0.110)$.

\section{Discussion}

Manpower is one of the most cherished assets of any department. Mental and physical resilience of workers is imperative for passable qualitative and quantitative output. Health of workers is not conceivable without optimum organizational environment $[9,10,18-20]$. Latter in turn boosts employees' motivation and morale, improves participation in decision making, and enriches creativity/innovation [16]. Workplace environment is a fundamental source of workers' mental health and vice versa [18]. Individuals contented with their place of work, colleagues and seniors tend to be more gratified with their profession. Job satisfaction validates less distress and better performance $[3,8$, 21]. Local researchers have reported burnout among health relief workers $[4,5,9]$, similar is the analysis by scientists form Turkey [11], Egypt [22], Mexico [23] and other countries [2, 7, 14]. Such doctors, nurses and paramedics cannot deliver their best services and cast subtle calamities to their clients $[4,9,18]$. 
Table 1. Relationship between job burnout and other variables $(n=250)$

\begin{tabular}{|c|c|c|c|c|c|c|c|}
\hline \multicolumn{2}{|c|}{ Variables } & \multirow[t]{2}{*}{ Total } & \multicolumn{3}{|c|}{ Level of Job Burnout n(\%) } & \multirow[t]{2}{*}{ Test value } & \multirow[t]{2}{*}{$p$-value } \\
\hline & & & Mild & Moderate & Severe & & \\
\hline \multirow[t]{2}{*}{ Gender } & Female & $111(44.4)$ & $74(44.3)$ & $31(48.4)$ & $6(31.6)$ & \multirow{2}{*}{$-0.227^{a}$} & \multirow{2}{*}{0.782} \\
\hline & Male & $139(55.6)$ & $93(55.7)$ & $33(51.6)$ & $13(68.4)$ & & \\
\hline \multirow{2}{*}{ Employment type } & Contracted & $148(59.2)$ & $96(57.5)$ & $39(60.9)$ & $13(68.4)$ & \multirow[t]{2}{*}{$2^{b}$} & \multirow[t]{2}{*}{0.672} \\
\hline & Official & $40(16.0)$ & $27(16.2)$ & $10(15.6)$ & $3(15.8)$ & & \\
\hline \multirow[t]{3}{*}{ Work experience } & $<5$ years & $75(30.0)$ & $51(30.5)$ & $16(25.0)$ & $8(42.1)$ & \multirow{3}{*}{$2^{b}$} & \multirow{3}{*}{0.48} \\
\hline & $5-10$ years & $48(19.2)$ & $29(17.4)$ & $14(21.9)$ & $5(26.3)$ & & \\
\hline & $>10$ years & $127(50.8)$ & $87(52.1)$ & $34(53.1)$ & $6(31.6)$ & & \\
\hline \multirow[t]{4}{*}{ Unit of work } & Treatment deputy & $24(9.6)$ & $18(10.8)$ & $3(4.7)$ & $3(15.8)$ & \multirow{4}{*}{$3^{b}$} & \multirow{4}{*}{0.222} \\
\hline & Health department & $72(28.8)$ & $42(25.1)$ & $24(37.5)$ & $6(31.6)$ & & \\
\hline & Development deputy & $95(38.0)$ & 70 (41.9) & $17(26.6)$ & $8(42.1)$ & & \\
\hline & Educational hospital & $59(23.6)$ & $37(22.2)$ & $20(31.3)$ & $2(10.5)$ & & \\
\hline \multirow[t]{3}{*}{ Organizational climate } & Weak & $28(11.2)$ & $12(42.9)$ & $12(42.9)$ & $4(14.2)$ & \multirow{3}{*}{$23.97^{\mathrm{c}}$} & \multirow{3}{*}{$<0.001$} \\
\hline & Moderate & $56(22.4)$ & $29(51.8)$ & $23(41.0)$ & $4(7.2)$ & & \\
\hline & Strong & $166(66.4)$ & $126(76.0)$ & $29(17.5)$ & $11(6.5)$ & & \\
\hline
\end{tabular}

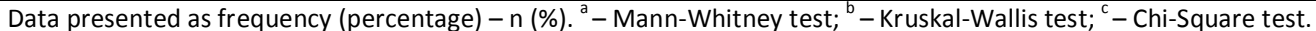

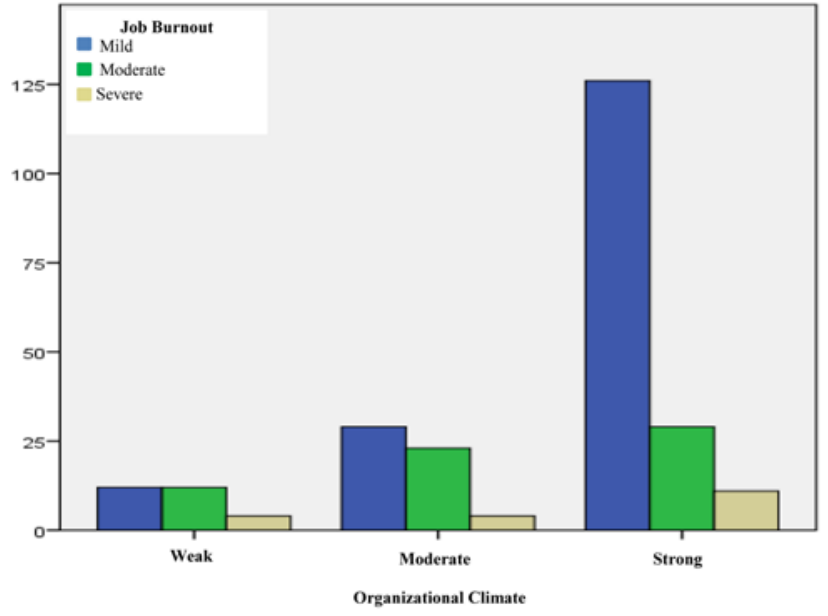

Figure 1. Inverse relation between Organizational climate levels and job burnout.

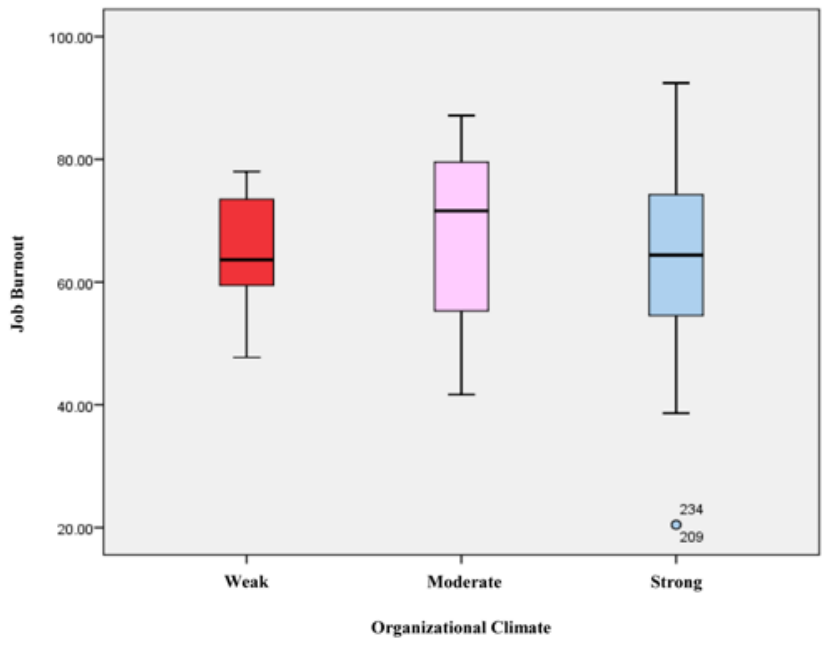

Figure 2. More consistent and less variable "Job Burnout" among participants with weak "Organizational Climate".
In this study, none of the participants was absolutely spared by professional burnout, moderate and severe levels of job burnout were revealed by $25.6 \%$ and $7.6 \%$ respectively. Such personnel can seldom yield their absolute to the customers. It is documented that $10 \%$ physicians are unsatisfied with their jobs [8]; more dissatisfied doctors harbored aggravated psychological distress [3, 24]. Eskandari et al. recognized professional burnout as a serious occupational concern, whilst more exhausted staff depicted poorer job satisfaction [25].

Data of this survey disclosed that $11.2 \%$ endorsed weak and 22.4\% revealed moderate organizational climate scores; while burnout and organizational climate were significantly inversely related, $14.2 \%$ of staff with weak organization had severe burnout. The role of environment in input or output of workers can never be overlooked. Organizational climate explicitly supplements every profession [8, 11]. No two work-units are identical. Any organization is unique in terms of its climate, goals, roles and expectations of its servants [15]. Organizational compatibility enhances motivation and accelerates chances of promotion [20]. It's one of the prime responsibilities of managers and higher officials to create and maintain a workable atmosphere. Soothing work environment travels down the chain.

Multiple demographic factors have been studied to analyze occupational distress and burnout $[8,11,24]$. This study did not reveal significant impact of age, gender, employment type, work experience and work unit on either burnout or organizational climate. Some literature revealed a reverse relation of degree of burnout with age and work experience $[3,8,11]$. It's candid that with age and stature, most of the goals are accomplished, aims accomplished and dreams fulfilled, so many people tend to feel the sense of satiety in professional life. Like our results, few researchers did not find considerable association between stress and gender, type of employment, nature of job, working hours or additional duties $[3,8]$. Others proclaimed staff burnout enroots if there's high workload, scarce manpower, time pressure, high expectations of customers, and other issues pertinent to system and procedures $[11,24]$. Low income has also been associated with psychosomatic challenges to health-care providers $[3,8]$, as majority of life targets cannot suffice without adequate credits. 


\section{Conclusion}

Considerable amount of professional burnout is triggered by deficient organizational climate. Imperative measures must be taken to improve and conserve high echelons of latter. Regular psychological assessment of members from every department is highly commended. It is opined that staff facing psychosomatic challenges must be offered apt professional expertise by relevant doctors. The care-givers should also undergo suitable screening and prompt management of psychosomatic ailments.

\section{Limitations}

It was not a generalized research as only one institute was incorporated. Selection and interview bias cannot be over-ruled. Analysis of more variables like income per capita and perceived social support could alter our results. Interviews of family members of participants, living environment, occupational status and comparison between government and private sectors could also generate interesting inferences. Nevertheless, this survey was first of its type to be conducted in concerned university utilizing internationally recognized and validated tools. The question posed was proved precise; it was more alarming that none of the respondents had adequate insight of psychosocial stressors. The hypothesis was partially justified as organizational climate was proved to be a strong accomplice to cause burnout, yet none of the other variables showed significant impact on outcomes. Basing on these data, scientists can explore similar populations locally and internationally, integration of multiple institutes at a time with bigger sample sizes and a spectrum of variables may harvest fruitful upshots.

\section{Conflicts of interest}

The authors declare that there are no conflicts of interests regarding the publication of this article.

\section{Ethical approval}

All procedures performed in studies involving human participants were in accordance with the ethical committee of Torbat Heydariyeh University of Medical Sciences (No.Ir.thums.rec.57.1394.57) and with the principles of the declaration of Helsinki (1964) and its later amendments or comparable ethical standards.

\section{Acknowledgments}

The authors would like to thank the Educational Deputy of Torbat Heydarieh University of Medical Sciences (Torbat Heydariyeh, Iran) and all the subjects who cooperated in the implementation of the research.

\section{References}

1. Guan S, Xiaerfuding $X$, Ning L, Lian $Y$, Jiang $Y$, Liu J, et al. Effect of job strain on job burnout, mental fatigue and chronic diseases among civil servants in the Xinjiang Uygur Autonomous Region of China. Int J Environ Res Pub Health 2017; 14(8): 872. https://dx.doi.org/10.3390/ijerph14080872.

2. Schaufeli WB, Maslach C, Marek T. Professional burnout: recent developments in theory and research: Taylor \& Francis, 2017.

3. Atif K, Khan HU, Malik AF. Do doctors have hidden distress; a study conducted at tertiary care hospital at Lahore. J Pak Med Assoc 2016; 66(1): 63-67. https://www.ncbi.nlm.nih.gov/pubmed/26712184.

4. Bozorgi F, Laali A, Mohammadi kia A. Prevalence and factors associated with burnout in emergency medical workers in Mazandaran University of Medical Sciences. J Mazandaran Univ Med Sci 2014; 24(112): 2-7. http://jmums.mazums.ac.ir/article-1-3306-en.html.

5. Masoudi R, Etemadifar S, Afzali SM, Kheri F, Hasanpour DA. The influential factors on burnout among nurses working in private hospitals in Tehran. Iranian Journal of Nursing Research 2008; 3(9): 4758. http://ijnr.ir/article-1-297-en.html.

6. Zhenxing G, Zhang J. Job burnout and psychological empowerment among Police in Mainland China. Iran J Public Health 2015; 44(7): 1014-1015. https://www.ncbi.nlm.nih.gov/pubmed/26576382.

7. Soler JK, Yaman H, Esteva M, Dobbs F, Asenova RS, Katić M, et al. Burnout in European family doctors: the EGPRN study. Fam Pract 2008; 25(4): 245-265. https://dx.doi.org/10.1093/fampra/cmn038.

8. Atif $\mathrm{K}, \mathrm{Khan} \mathrm{HU}$, Maqbool $\mathrm{S}$. Job satisfaction among doctors, a multifaceted subject studied at a tertiary care hospital in Lahore. Pak J Med Sci 2015; 31(3): 610. https://dx.doi.org/10.12669/pims.313.7402.

9. Dargahi H, Musavi M, Shaham G. Organizational climate of hospitals at Tehran university of medical sciences. J Health Admin 2013; 15(50): 31-40. http://iha.iums.ac.ir/article-1-952-en.html.

10. Choudhury G. The dynamics of organizational climate: An exploration. Management Insight 2012; 7(2): 111-116. http://citeseerx.ist.psu.edu/viewdoc/download?doi=10.1.1.1028.4693 \&rep=rep $1 \&$ type $=$ pdf.

11. Gemlik N, Sisman FA, Sigri U. The relationship between burnout and organizational commitment among health sector staff in Turkey. Journal of Global Strategic Management 2010; 4(2): 137-149. https://dx.doi.org/10.20460/JGSM.2010415831.

12. Rostami Z, Abedi MR, Schaufeli WB, Ahmadi SA, Sadeghi AH. The psychometric characteristics of Maslach burnout inventory student survey: a study students of Isfahan University. Zahedan J Res Med Sci 2014; 16(9): 55-58. http://zjrms.ir/article-1-2172-en.html.

13. Sussman $L$, Deep $S$. The communication experience in human relations. $2^{\text {nd }}$ edition. Cincinnati Ohio, South-Western Publishing Co: 214-216.

14. Maslach C, Schaufeli WB, Leiter MP. Job burnout. Ann Rev Psychol 2001; 52(1): 397-422. https://doi.org/10.1146/annurev.psych.52.1.397.

15. Bahrami MA, Taheri G, Montazeralfaraj R, Tafti AD. The relationship between organizational climate and psychological well-being of hospital employees. World J Med Sci 2013; 9(1): 61-67. https://dx.doi.org/10.5829/idosi.wjms.2013.9.1.75152.

16. Pourhashemi SE, Janani H. Correlation between organizational climate and organizational support of physical education professors of Ardabil province. J Appl Environ Biol Sci 2015; 5(7S): 164-167. https://www.textroad.com/pdf/JAEBS/J.\%20Appl.\%20Environ.\%20Biol \%20Sci.,\%205(7S)164-167,\%202015.pdf.

17. Foladvand $\mathrm{K}$. The relationship between organizational climate and the mental health of hospital workers in Ilam State Hospitals. Journal of Ilam University of Medical Sciences 2007; 15(1): 44-50. http://sjimu.medilam.ac.ir/article-1-20-en.html.

18. Pourezzat AA, Ehsani MN, Yazdani HR, Faez K. Comparative analyze of the impact of several dimensions of organizational justice on organizational climate and organizational loyalty: a research on an IT based organization. J Pub Admin 2013; 5(1): 65-88. https://dx.doi.org/10.22059/jipa.2013.35548.

19. Zheng W, Yang B, McLean GN. Linking organizational culture, structure, strategy, and organizational effectiveness: Mediating role of knowledge management. J Business Res 2010; 63(7): 763-771. https://EconPapers.repec.org/RePEc:eee:jbrese:v:63:y:2010:i:7:p:763771.

20. Zhang J, Liu Y. Organizational climate and its effects on organizational variables: an empirical study. Int J Psychol Studies 2010; 2(2): 189-201. http://dx.doi.org/10.5539/ijps.v2n2p189.

21. Çelik S, Dedeoglu BB, Inanir A. Relationship Between ethical leadership, organizational commitment and job satisfaction at hotel organizations. Ege Akademik Bakis 2015; 15(1): 53. https://EconPapers.repec.org/RePEc:ege:journl:v:15:y:2015:i:1:p:53$\underline{65}$ 
22. Abdo S, El-Sallamy R, El-Sherbiny A, Kabbash I. Burnout among physicians and nursing staff working in the emergency hospital of Tanta University, Egypt. East Mediterr Health J 2015; 21(12): 906. https://www.ncbi.nlm.nih.gov/pubmed/26996364.

23. Costa PL, Passos AM, Silva SA, Sacadura-Leite E, Tavares SM, Spanu F, et al. Overcoming job demands to deliver high quality care in a hospital setting across Europe: The role of teamwork and positivity. Rev Psicol Trab Organ 2014; 30(3): 105-112. https://doi.org/10.1016/j.rpto.2014.11.001.

24. Shahmoradi M, Rezaee Z, Sheikhi S, Darabian S. The relationship between organizational climate, organizational culture and creativity with job satisfaction of librarians in Ahwaz public libraries. Res J Psycho Edu Sci 2016; 2(4): 94-101. http://www.rjpes.com/fulltext/paper13052016112240.pdf.

25. Eskandari D, Jafari MJ, Mehrabi Y, Kian MP, Charkhand H, Mirghotbi M. A qualitative study on organizational factors affecting occupational accidents. Iran J Public Health 2017; 46(3): 380-388. https://www.ncbi.nlm.nih.gov/pubmed/28435824.

Authors:

Iman Seyedmoharrami - MSc, Counseling Unit, Torbat Heydariyeh University of Medical Sciences, Torbat Heydariyeh, Iran; PhD Student of counseling, Department of Counseling, Ferdowsi University of Mashhad, Mashhad, Iran. https://orcid.org/0000-0002-1358-4899.

Khaula Atif - Health Care Administrator, Department of General Administration, National University of Medical Sciences, Rawalpindi, Pakistan. https://orcid.org/0000-0002-4977-4459.

Maryam Tatari - Lecturer, Department of Biostatistics, School of Public Health, Torbat Heydariyeh University of Medical Sciences, Torbat Heydariyeh, Iran. https://orcid.org/0000-0002-3201-1164.

Sedigheh Abbaspour - Lecturer, Department of Nursing, School of Nursing and Midwifery, Torbat Heydariyeh University of Medical Sciences, Torbat Heydariyeh, Iran. https://orcid.org/0000-0001-5131-9685.

Anahita Zandi - Lecturer, Department of Nursing, School of Nursing and Midwifery, Torbat Heydariyeh University of Medical Sciences, Torbat Heydariyeh, Iran. https://orcid.org/0000-0001-6055-0096.

Gholamheidar Teimori-Boghsani - MSc, Department of Environmental and Occupational Health Engineering, School of Public Health, Torbat Heydariyeh University of Medical Sciences, Torbat Heydariyeh, Iran. https://orcid.org/0000-0003-4908-4324.

Abbas Ghodrati-Torbati - Lecturer, Department of Nursing, School of Nursing and Midwifery, Torbat Heydariyeh University of Medical Sciences, Torbat Heydariyeh, Iran. https://orcid.org/0000-0003-0330-1258. 